\title{
Validity of Visual Vector Relationship for the Clinical Assessment of Anterior Malar Projection and the Changes Observed in Facemask Therapy Patients" - A Retrospective Stud
}

\author{
Dr. Jomin Jose ${ }^{1}$, Dr. Nandini Nelivigi ${ }^{2}$, Dr. Sandesh S. Pai ${ }^{3}$, Dr.Vinaya Pai ${ }^{4}$, \\ Dr. Vishwanath A E ${ }^{5}$, Dr Manju Prasad ${ }^{6}$, Dr. Suhas ${ }^{7}$ \\ ${ }^{1}$ III Mds Pg Student Dept of Orthodontics Vydehi Institute of Dental Sciences and Research Centre \\ ${ }^{2}$ Professor Dept of Orthodontics Vydehi Institute of Dental Sciences and Research Centre \\ ${ }^{3}$ Professor and Head Dept of Orthodontics Vydehi Institute of Dental Sciences and Research Centre \\ ${ }^{4}$ Principal Bangalore Institute of Dental Science \\ ${ }^{5}$ Associate Professor Dept of Orthodontics Vydehi Institute of Dental Sciences and Research Centre \\ ${ }^{6}$ Senior Lecturer Dept of Orthodontics Vydehi Institute of Dental Sciences and Research Centre \\ ${ }^{7}$ Senior Lecturer Dept of Orthodontics Vydehi Institute of Dental Sciences and Research Centre \\ Department(S) And Institution(S) : Dept. of Dentofacial Orthodontics And Orthopaedics \\ Vydehi Institute of Dental Sciences and Research Centre.
}

\begin{abstract}
Aims: The present study was undertaken to evaluate whether a visual classification of anterior malar support using vector relationship is supported by cephalometric analysis and to assess the effects of face mask therapy on vector relationship and other cephalometric variables.

Methods and Material: Pre-treatment profile photographs and lateral cephalograms of forty adult subjects (20 positive vector and 20 negative vector) were collected.

Pre-treatment and post-treatment profile photographs and lateral cephalograms of 20 patients successfully treated by facemask therapy were collected.

Traditional cephalometric measurements were used to describe changes between pretreatment, posttreatment lateral cephalograms and profile photographs.

Statistical analysis used: Student's unpaired t test were used to compare the differences between SNO measurements for group $A$ and group $B$ and paired t-test was done to compare the pre-treatment and posttreatment lateral cephalograms.

Results: Between the positive and negative group, an analysis for sexual dimorphism showed no statistically significant difference. Differences in skeletal support between the negative and positive vector groups assessed using SNO angles $\left(4.6^{\circ}\right)$ were highly significant. SNO angulations in the negative vector group were smaller than the positive vector controls by an average of $4.6^{\circ}$.

Conclusions: The null hypothesis of the study that there is no significant difference between face mask therapies on visual vector relationship is rejected because though face mask protraction therapy did not make a negative vector patient to positive vector, there was significant improvement in the malar projection.
\end{abstract}

Key-words: Visual vector relationship, anterior malar projection, facemask, retrospective.

\section{Introduction}

Attaining optimal facial attractiveness is one of the primary goals of orthodontic treatment. Facial examination is important to accomplish this so that the orthodontic correction will not adversely affect the normal facial traits. Orthodontic treatment involves 2 goals of bite correction and attractiveness hence the treatment planning is difficult. Sometimes in the process of correcting the bite there can be decrease of facial attractiveness. This result if occurs, is either due to lack of understanding of what is desirable as an aesthetic goal or lack of attention to facial esthetics. ${ }^{1}$

Person's facial attractiveness is determined by skeletal mass of the face. The nose, the chin and the two malar eminences are three promontories that determine facial features.

Shape of the lateral segment of the middle third of the face is decided by malar contour. The "social profile" is the terminology used for the three quarter profile ${ }^{2}$. Round and full malar prominence is considered as attractive. A premature look is a contribution of flat hypoplastic malar region which makes the face appear dull and uninteresting. Strong cheekbones make the face appear young.

A curved line starting at a point just anterior to the ear and extends anterior-inferiorly, ending adjacent to the alar base of the nose decides the cheek bone contour. The cheek bone - nasal base - lip contour complex forms a smooth continuous, anteriorly facing curved line. To improve the appearance of patients with flat malar 
eminence augmentation has been proposed. This creates a more youthful look as it makes the face more oval and deemphasizes prominent nasal or mental profiles. ${ }^{2}$

Cephalometrics has concerned itself with the study of the relationship of the maxilla to the cranial base (SNA angle) as well as the relationship of the mandible to the cranial base (SNB angle), and the relation of the mandible to the maxilla (ANB angle). The lateral cephalometric radiograph does not show the malar eminence but it is, in fact, always lateral and inferior to the orbitale. Hence, if the position of orbitale was known in relation to nasion and A point, this would tell us the relationship of the malar eminence to these latter positions. ${ }^{3}$ Aesthetic problems can result when we completely rely on cephalometric dentoskeletal analysis for treatment planning. More are the chances of this happening when the orthodontist tries to predict soft tissue outcome using only hard tissue normal values. The soft tissue covering the bones and teeth can vary so greatly that the dentoskeletal pattern may be an inappropriate guide in evaluating facial disharmony. Skeletal norms define treatment need and stability goals. The soft tissue appearance is only partially dependent on the underlying skeletal structure. The orthodontist must understand soft tissue behaviour in relation to orthopaedic and orthodontic changes and must also take into consideration growth and development of soft tissue traits to accurately predict soft tissue response to hard tissue changes. ${ }^{1}$

Additionally, skeletal structures of the midface are difficult to assess in lateral cephalograms, and this has led orthodontists to focus entirely on the premaxilla for classification of maxillary skeletal development. ${ }^{4}$

Hence this study seeks to determine whether visual classification of anterior malar projection using vector relationship is supported by cephalometric analysis and to know the effects of face mask therapy on visual relationship. Thus, the null hypothesis of the study is that there is no statistically significant difference between face mask therapy and visual vector relationship subjects.

Method of collection of data

\section{Materials And Methods}

The data was collected as two parts

\section{Part I}

1. 20 adult subjects (10 males and 10 females) having positive vector relationship were selected randomly from patients.

2. 20 adult subjects (10 males and 10 females) having negative vector relationship were selected from patients.

\section{Exclusion criteria}

1. Patients with craniofacial syndromes

2. Patients having cleft lip and cleft palate

Lateral cephalograms and Extra-oral photographs were taken for each subject from their initial records. In order to quantify skeletal support for each subject, sella-nasion-orbitale (SNO) angulations were used to evaluate the anteroposterior position of the malar eminence relative to the cranial base.

This measurement was selected according to the previous works of Leonard and Walker. ${ }^{2}$ The key ridge and the maxillary sinus were used as guides to consistently locate this landmark. All cephalograms were traced by one examiner.

Cephalometric Analysis: The following measurements were made on the cephalograms - SNO angle,Visual vector relationship,SNAangle,Angle of convexity,Ar- Ptm,Co- A,A-N perpendicular,Soft tissue convexity(N/-A/-Pog/) and Soft tissue maxillary prognathism(G/-Sn).

Sella-nasion-orbitale (SNO) angulations were measured to evaluate the subject's anteroposterior position of the malar eminence relative to the cranial base.

\section{Part II}

The second part of the study consisted of records of 20 subjects, 10 male and 10 female (between 9 to 13 years), which were collected from various dental colleges in Bangalore based on these criteria:

1) Pretreatment and post treatment lateral cephalograms of patients treated with face mask therapy taken on the same cephalostat and of good quality.

2) The selected cases were developing Class III malocclusion identified by a combination of an ANB measurement of less than $1^{\circ}$ and edge-to edge incisor relationship or anterior crossbite.

3) The selection criteria for successful face mask therapy included

a. A change in ANB angle by a minimum of $3^{0}$.

b. Correction of negative overjet to positive overjet.

Pretreatment and posttreatment lateral cephalograms were traced side by side to provide consistent identification and location of landmarks between them. 
Lateral cephalograms were traced by the same investigator under optimal conditions with a $0.5 \mathrm{~mm}$ lead pencil on dimensionally stable cephalometric tracing acetate sheets. All tracings were registered at sella and rotated $7^{\circ}$ down from the sella-nasion line to establish a horizontal reference plane and approximate Frankfort horizontal.

\section{Cephalometric Analysis:}

Traditional cephalometric measurements were used to describe changes between pretreatment and posttreatment lateral cephalograms. In the cases selected, pre-treatment and post-treatment lateral cephalograms and profile photographs were analyzed to assess the changes observed by face mask therapy. The parameters measured were SNO angle,Visual vector relationship, SNA angle, Angle of convexity, Ar- Ptm, Co- A, A-N perpendicular, Soft tissue convexity(N/-A/-Pog/), Soft tissue maxillary prognathism(G/-Sn).

Pre-treatment and post treatment lateral cephalograms and Extra-oral profile photographs of 20 Class III patients successfully treated with face mask therapy between the age group of 9 and 13 years were taken from various Institutions.

In the cases selected, Group A and Group B lateral cephalograms and profile photographs and in Group $\mathrm{C}$ pre-treatment and post-treatment lateral cephalograms and profile photographs were analysed to assess the changes observed by face mask therapy.

\section{Results}

Table I compares the pre and post treatment cephalometric measurements of face mask therapy patients using student's paired t test. Most of the parameters showed statistically significant results on treatment with face mask therapy. For the pre treatment versus post treatment group, all the skeletal parameters other than A - N Perpendicular and soft tissue parameters except soft tissue maxillary prognathism $\left(G^{\prime}-S n\right)$ showed statistically significant treatment results depicting that correction of the malocclusion occurred by anterior displacement of the skeletal structures.

\begin{tabular}{|c|c|c|c|c|c|c|c|c|c|c|c|}
\hline \multirow[b]{2}{*}{ Variables } & \multirow{2}{*}{$\begin{array}{l}\text { Time } \\
\text { Period }\end{array}$} & \multirow[b]{2}{*}{$\mathrm{N}$} & \multirow[b]{2}{*}{ Mean } & \multirow[b]{2}{*}{ SD } & \multirow{2}{*}{ S.E.M } & \multirow{2}{*}{ Mean } & \multicolumn{2}{|c|}{$95 \% \mathrm{Cl}$ of the Diff } & \multirow[b]{2}{*}{$\mathrm{T}$} & \multirow[b]{2}{*}{$\mathrm{df}$} & \multirow[b]{2}{*}{ P-value } \\
\hline & & & & & & & Lower & Upper & & & \\
\hline \multirow[t]{2}{*}{ ANB ANGLE } & Pre & 20 & -4.40 & 1.57 & 0.35 & \multirow{2}{*}{-4.55} & \multirow{2}{*}{-5.37} & \multirow{2}{*}{-3.73} & \multirow{2}{*}{-11.55} & \multirow{2}{*}{19} & \multirow{2}{*}{$<0.001 *$} \\
\hline & Post & 20 & 0.15 & 1.63 & 0.37 & & & & & & \\
\hline \multirow[t]{2}{*}{ SNO ANGLE } & Pre & 20 & 52.45 & 4.03 & 0.90 & \multirow{2}{*}{-3.25} & \multirow{2}{*}{-4.44} & \multirow{2}{*}{-2.06} & \multirow{2}{*}{-5.695} & \multirow{2}{*}{19} & \multirow{2}{*}{$<0.001 *$} \\
\hline & Post & 20 & 55.70 & 3.94 & 0.88 & & & & & & \\
\hline \multirow[t]{2}{*}{ SNA ANGLE } & Pre & 20 & 75.90 & 3.31 & 0.74 & \multirow{2}{*}{-3.65} & \multirow{2}{*}{-4.30} & \multirow{2}{*}{-3.00} & \multirow{2}{*}{-11.76} & \multirow{2}{*}{19} & \multirow{2}{*}{$<0.001 *$} \\
\hline & Post & 20 & 79.55 & 2.74 & 0.61 & & & & & & \\
\hline \multirow{2}{*}{$\begin{array}{c}\text { ANGLE OF } \\
\text { CONVEXITY }\end{array}$} & Pre & 20 & -10.23 & 5.45 & 1.22 & 733 & 043 & 522 & 7276 & 10 & $<0001 *$ \\
\hline & Post & 20 & -2.90 & 3.39 & 0.76 & & & & & & \\
\hline Ar-Ptm & Pre & 20 & 28.30 & 2.90 & 0.65 & 185 & 262 & 107 & 4075 & 11 & 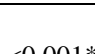 \\
\hline & Post & 20 & 30.15 & 2.37 & 0.53 & & & & & & \\
\hline Co-A & Pre & 20 & 72.53 & 5.19 & 1.16 & -478 & 500 & 365 & 8006 & 10 & $<0001 *$ \\
\hline & Post & 20 & 77.30 & 5.47 & 1.22 & & & & & & \\
\hline $\begin{array}{c}\text { A-N } \\
\text { A }\end{array}$ & Pre & 20 & -0.10 & 5.52 & 1.24 & 048 & 184 & 080 & 073 & 10 & 047 \\
\hline & Post & 20 & 0.38 & 4.16 & 0.93 & & & & & & \\
\hline $\mathrm{N}^{i}-\mathrm{A}^{i}-\mathrm{Pog}^{i}$ & Pre & 20 & 4.85 & 4.59 & 1.03 & $-7,10$ & -926 & -4.94 & -6871 & 19 & $<0001^{*}$ \\
\hline & Post & 20 & 11.95 & 5.23 & 1.17 & & & & & & \\
\hline $\mathrm{G}^{i}-\mathrm{Sn}$ & Pre & 20 & 4.00 & 2.38 & 0.53 & -115 & -237 & 0.07 & -1977 & 19 & 0.06 \\
\hline & Post & 20 & 5.15 & 3.10 & 0.69 & & & & & & \\
\hline
\end{tabular}

Table I: Comparison Of Pre And Post Rx Cephalometric Values Of Face Mask Therapy Patients Using Student's Paired T Test. 
Validity of visual vector relationship for the clinical assessment of anterior malar projection and...

\begin{tabular}{|c|c|c|c|c|c|c|c|c|c|c|c|}
\hline \multicolumn{12}{|c|}{ Comparison of the cephalometric values between Positive and Negative vectors using student unpaired t test } \\
\hline \multirow[t]{2}{*}{ Variables } & \multirow[t]{2}{*}{ Vector } & \multirow[t]{2}{*}{$\mathrm{N}$} & \multirow[t]{2}{*}{ Mean } & \multirow[t]{2}{*}{ SD } & \multirow[t]{2}{*}{ S.E.M } & \multirow[t]{2}{*}{ Mean } & \multicolumn{2}{|c|}{$95 \% \mathrm{Cl}$ of the Diff } & \multirow[t]{2}{*}{$\mathrm{t}$} & \multirow[t]{2}{*}{$\mathrm{df}$} & \multirow[t]{2}{*}{ P-value } \\
\hline & & & & & & & Lower & Upper & & & \\
\hline \multirow[t]{2}{*}{ SNO ANGLE } & Positive & 20 & 56.3 & 3.2 & 0.7 & \multirow[t]{2}{*}{4.6} & \multirow[t]{2}{*}{2.66} & \multirow[t]{2}{*}{6.54} & \multirow[t]{2}{*}{4.804} & \multirow[t]{2}{*}{38} & \multirow[t]{2}{*}{$<0.001^{*}$} \\
\hline & Negative & 20 & 51.7 & 2.8 & 0.6 & & & & & & \\
\hline \multirow[t]{2}{*}{ SNA ANGLE } & Positive & 20 & 82.7 & 2.0 & 0.4 & \multirow[t]{2}{*}{5.1} & \multirow[t]{2}{*}{3.43} & \multirow[t]{2}{*}{6.77} & \multirow[t]{2}{*}{6.172} & \multirow[t]{2}{*}{38} & \multirow[t]{2}{*}{$<0.001^{*}$} \\
\hline & Negative & 20 & 77.6 & 3.1 & 0.7 & & & & & & \\
\hline \multirow{2}{*}{$\begin{array}{l}\text { ANGLE OF } \\
\text { CONVEXITY }\end{array}$} & Positive & 20 & 5.6 & 4.1 & 0.9 & \multirow[t]{2}{*}{14.7} & \multirow[t]{2}{*}{11.56} & \multirow[t]{2}{*}{17.80} & \multirow[t]{2}{*}{9.52} & \multirow[t]{2}{*}{38} & \multirow[t]{2}{*}{$<0.001 *$} \\
\hline & Negative & 20 & -9.1 & 5.5 & 1.2 & & & & & & \\
\hline \multirow[t]{2}{*}{ Ar-Ptm } & Positive & 20 & 35.1 & 3.4 & 0.8 & 1.7 & -0.63 & 3.93 & 1.468 & 38 & 0.15 \\
\hline & Negative & 20 & 33.4 & 3.7 & 0.8 & & & & & & \\
\hline Co-A & Positive & 20 & 91.6 & 7.2 & 1.6 & 8.9 & 3.95 & 13.85 & 3.642 & 38 & $0.001^{*}$ \\
\hline & Negative & 20 & 82.7 & 8.2 & 1.8 & & & & & & \\
\hline A-N & Positive & 20 & 2.3 & 2.5 & 0.6 & 9.1 & 7.39 & 10.71 & 11.016 & 38 & $<0.001^{*}$ \\
\hline perpendicular & Negative & 20 & -6.8 & 2.7 & 0.6 & & & & & & \\
\hline $\mathrm{N}^{i}-\mathrm{A}^{i}-\mathrm{Pog}^{i}$ & Positive & 20 & 19.3 & 3.9 & 0.9 & 16.8 & 12.66 & 20.84 & 8.286 & 38 & $<0.001 *$ \\
\hline & Negative & 20 & 2.5 & 8.2 & 1.8 & & & & & & \\
\hline $\mathrm{G}^{i}-\mathrm{Sn}$ & Positive & 20 & 9.8 & 6.0 & 1.3 & 4.0 & 0.95 & 6.95 & 2.669 & 38 & $0.01 *$ \\
\hline & Negative & 20 & 5.8 & 2.8 & 0.6 & & & & & & \\
\hline
\end{tabular}

Table II: Comparison Of The Cephalometric Values Between Positive And Negative Vectors Using Student's Unpaired T Test

Table II shows that there were statistically significant differences in skeletal and soft tissue parameters between positive and negative vector groups (SNA Mean $5.1^{\circ} \mathrm{P}<0.001$; Angle of convexity Mean $14.7^{0} \mathrm{P}<0$ .001; Ar to Ptm Mean 1.7 P =0 .15; Nasion perp to A-point Mean 9.1 P < 0.001; Soft tissue convexity $\left(\mathrm{N}^{\prime}-\mathrm{A}^{\prime}\right.$ $\mathrm{Pog}^{\prime}$ ) Mean $\left.16.8^{0} \mathrm{P}<0.001\right)$. Condylion to point $\mathrm{A}(\mathrm{Mean} 8.9 \mathrm{P}=0.001)$ and soft tissue maxillary prognathism $\left(G^{\prime}-S n\right)$ Mean $4 \mathrm{p}=0.01$ did not show statistically significant differences.

\section{Discussion}

One of the most difficult malocclusions to correct in orthodontics is Class III skeletal anomaly. Some investigators have used chin cups to correct these Class III skeletal patterns. However, mandibular treatment alone is not sufficient to correct retrognathic maxillary position. Protraction of nasomaxillary complex in skeletal Class III cases will also be required.

The Delaire mask was popularized to protract the maxilla in the late 1960. But in these cases upward and forward rotation of maxilla and downward and backward rotation of mandible were also observed. Petit modified the Delaire mask in 1983 and it consisted of a forehead pad and a chin pad that were connected with a heavy steel rod. A bonded rapid palatal expansion appliance was used intraorally. Forward traction of the maxilla was accomplished by rubber bands. The treatment results produced by this appliance were the anterior movement of the maxilla and downward and backward rotation of the mandible. ${ }^{5}$ McNamara in $1987^{10}$ introduced the use of bonded acrylic expansion appliance with acrylic occlusal coverage for maxillary protraction. ${ }^{10}$ Patient cooperation was improved by Turley by fabricating customized facemasks ${ }^{11}$. McNamara and Turley ${ }^{11}$ have recommended the use of bonded rapid palatal expansion appliance for several days before beginning protraction in order to facilitate maxillary movement. After active protraction of the maxilla, retention is vitally important in maintaining the treatment effects of the facemask. Petit ${ }^{11}$ suggested the Fränkel III regulator be used for 6 months post protraction. The maxilla moves downward and forward with a slight upward movement in the anterior and downward movement in the posterior palatal plane as a result of protraction force, at the same time posterior teeth extrude little.Hence downward and backward rotation of the mandible improves the maxillomandibular skeletal relationship in the sagittal dimension but results in an increase in lower anterior facial height. This rotation is a major contributing factor in establishing an anterior overjet improvement.

The main principle of maxillary protraction is to apply tensile force on the circumaxillary sutures which thereby stimulate bone apposition in the suture areas. Subsequently, the maxillary teeth become the point of force application, and the face (forehead, chin, zygoma) or occipital area becomes the anchorage source.

The present study was undertaken to evaluate whether a visual classification of anterior malar support using vector relationship is supported by cephalometric analysis and to assess the effects of face mask therapy on vector relationship and other cephalometric variables.

Between the positive and negative group, an analysis for sexual dimorphism showed no statistically significant difference between genders in any of the skeletal and soft tissue parameters. Differences in skeletal support between the negative and positive vector groups assessed using SNO angles $\left(4.6^{\circ}\right)$ were highly significant. SNO angulations in the negative vector group were smaller than the positive vector controls by an average of $4.6^{0}$. 
A controlled randomized clinical trial was done to measure the effects of maxillary protraction with or without palatal expansion. Comparisons of treated and control subjects showed significant treatment effects beyond normal Class III growth. The study results showed a $2 \mathrm{~mm}$ additional forward displacement of the maxillary complex with counterclockwise rotation, mandibular clockwise rotation, posterior movement of Bpoint by an average of $1.5 \mathrm{~mm}$, and forward movement of the maxillary dentition of nearly $1 \mathrm{~mm} .{ }^{6}$

In our present study also protraction face mask therapy proved to improve the skeletal convexity and these changes were evident on the posttreatment soft tissue cephalometric measurements. ANB angle showed an improvement of $4.5^{\circ}$. There was forward displacement of the maxillary complex.

By studying the cephalometric changes in 129 subjects with conditions diagnosed as skeletal Class III malocclusion in a study theyevaluated the effect of maxillary protraction on facial growth. who had been treated with maxillary protraction were compared to 9 male and 12 female subjects with annual cephalometric records from the Yonsei growth study sample. The control subjects had Angle Class I malocclusions with normal overjet and overbite. More maxillary forward displacement and mandibular growth inhibition were observed in the protraction group during treatment, and the difference from the untreated controls was statistically significant. No statistical difference was observed when changes due to treatment according to ages were compared $^{7}$

Similar to this study our present study also demonstrated maxillary forward displacement due to combined skeletal and soft tissue changes. It signifies the effectiveness of face mask therapy in maxillary protraction.

The current study demonstrated a significant response to face mask therapy, which affected many areas of the dentofacial complex. Skeletal change was primarily a result of anterior and vertical movement of the maxilla. The results confirmed a true maxillary orthopedic effect resulting from treatment. Various soft tissue changes combined to improve the Class III profile and profile becoming more convex. The observed soft tissue effects appeared to result from the induced skeletal changes.

This study showed that significant dentoskeletal changes and improvements in dentofacial profile resulted from 6 months of treatment with maxillary expansion and protraction. ${ }^{8}$

In the present study we evaluated the ability of the protraction face mask to improve the vector relationship and to evaluate whether face mask therapy can change the negative vector to positive. The results showed that the skeletal changes by maxillary protraction was not sufficient enough to bring a negative vector patient to positive. Even though positive vector was not achieved there was definitive improvement in the malar prominence. The improvement in the malar prominence was supported by the cephalometric values of the present study.

Deficient malar and midfacial projection leaves the soft tissues poorly supported, resulting in premature lower lip and cheek descent. This also causes visible bags and a more aged appearance. ${ }^{9}$

The results of the present study demonstrated the effects of face mask therapy and validity of visual vector relationship for clinical assessment of malar prominence. But further radiographic examinations are required to evaluate the extent of malar deficiency mainly when surgical correction of the defect is in the treatment. Visual vector relationship can only be used as a clinical diagnostic tool for gross assessment of malar deficiency.

In the same study wedetermined whether a visual classification of anterior malar support using vector relationships is supported by cephalometric analysis. The present study also compared the angular measurement SNO between positive and negative vector groups which was found to be highly significant $(\mathrm{p}<$ 0.0001 ). The mean difference of SNO angle between these groups were $4.6^{0}$. But when compared between male and female, it does not have any gender differences. The vector relationships are an effective means of classifying anterior malar support during macroesthetic evaluation of the patient.

\section{Conclusion}

The results of the present study demonstrated the effects of face mask therapy and validity of visual vector relationship for clinical assessment of malar prominence.

The following conclusions are drawn from the study:

- Face mask protraction therapy is an effective treatment modality for maxillary retrognathism.

- There is definitive orthopaedic effect which makes the maxilla grow anteriorly.

- The face mask therapy has the potential to make the profile more convex.

- These improvements in the profile are more due to skeletal and soft tissue changes.

- As a result of these changes a positive overjet could be achieved in reverse overjet patients.

- Even though a positive vector relationship could not be achieved in most of the cases, there was definitive improvement in the malar prominence.

- Visual vector relationship is an effective clinical assessment of anterior malar projection and it is supported by cephalometric analysis.

- There was no statistically significant sexual dimorphism between the positive or negative vector groups. 
But further radiographic examinations are required to evaluate the extent of malar deficiency mainly when surgical correction of the defect is planned. Visual vector relationship can only be used as a clinical diagnostic tool for gross assessment of malar deficiency.

\section{References}

[1]. Bergman RT. Cephalometric soft tissue facial analysis: Am J OrthodDentofacOrthop 1999;116:373-89

[2]. Robiony M, Costa F, Demtri V, Politi M. Simultaneous Malaroplasty with porous polyethylene implants and orthognathic surgery for correction of malar deficiency: J Oral MaxillofacSurg 1998:56: 734-741.

[3]. Leonard MS, Walker GF. A cephalometric study of the relationship between the malar bones and the maxilla in white American females. Angle Orthod.1977;47(1):42-5.

[4]. Frey S T. New diagnostic tenet of the esthetic midface for clinical assessment of anterior malar projection: Angle Orthod. 2013;83:790-794

[5]. Alcan T, Keles A, Erverdi N. The effects of a modified protraction headgear on maxilla. Am J OrthodDentofacOrthop 2000;117:2738 .

[6]. Vaughn GA, Mason B, Moon HB, Turley PK. The effects of maxillary protraction therapy with or without rapid palatal expansion: A prospective,randomized clinical trial: Am J OrthodDentofacOrthop 2005;128:299-309

[7]. Sung S J, Baik HS. Assessment of skeletal and dental changes by maxillary protraction: Am J OrthodDentofacOrthop 1998;114:492-502.

[8]. Ngan P, Hagg U, Yiu C, Merwin D, Stephen HY. Soft tissue and dentoskeletal profile changes associated with maxillary expansion and protraction headgear treatment: Am J OrthodDentofacOrthop 1996;109:38-49.

[9]. Frey S T. New diagnostic tenet of the esthetic midface for clinical assessment of anterior malar projection: Angle Orthod. 2013;83:790-794.

[10]. Baccetti T, McGill JS, Franchi L, MaNamara JA, Tollaro I. Skeletal effects of early treatment of Class III malocclusion with maxillary expansion and face-mask therapy: Am J OrthodDentofacOrthop 1998;113:333-43.

[11]. Alcan T, Keles A, Erverdi N. The effects of a modified protraction headgear on

[12]. maxilla. Am J OrthodDentofacOrthop 2000;117:27-38. 